\title{
A trend analysis of surgical operations under a global payment system in Tehran, Iran (2005-2015)
}

\author{
Faranak Behzadi Goudari ${ }^{1}$, Arash Rashidian², Mohammad Arab ${ }^{3}$, Mahmood Mahmoudi ${ }^{4}$, Ebrahim
} Jaafaripooyan $^{5}$

\begin{abstract}
${ }^{1}$ Assistant Professor of Health Policy, Health Services Management Research Center, Institute for Futures Studies in Health, Kerman University of Medical Sciences, Kerman, Iran

${ }^{2}$ Ph.D. of Health Policy, Professor, Department of Health Management and Economics, School of Public Health, Tehran University of Medical Sciences, Tehran, Iran

${ }^{3}$ Ph.D. of Healthcare Management, Professor, Department of Health Management and Economics, School of Public Health, Tehran University of Medical Sciences, Tehran, Iran

${ }^{4}$ Ph.D. of Medical Demography, Professor, Department of Epidemiology and Biostatistics, School of Public Health, Tehran University of Medical Sciences, Tehran, Iran

${ }^{5}$ Ph.D. of Healthcare Management, Associate Professor, Department of Health Management and Economics, School of Public Health, Tehran University of Medical Sciences, Tehran, Iran
\end{abstract}

\section{Type of article: Original}

\begin{abstract}
Background: Global payment system is a first example of per-case payment system that contains 60 commonly used surgical operations for which payment is based on the average cost per case in Iran.

Objective: The aim of the study was to determine the amount of reduction, increase or no change in the trend of global operations.

Methods: In this retrospective longitudinal study, data on the 60 primary global surgery codes was gathered from Tehran Health Insurance Organization within the ten-year period of 2005-2015 separately, for each month. Out of 60 surgery codes, only acceptable data for 46 codes were available based on the insurance documents sent by medical centers. A quantitative analysis of time series through Regression Analysis Model using STATA software v.11 was performed.

Results: Some global surgery codes had an upward trend and some were downwards. Of N Codes, N83, N20, $\mathrm{N} 28, \mathrm{~N} 63$, and $\mathrm{N} 93$ had an upward trend $(\mathrm{p}<0.05)$ and N32, N43, N81 and N90 showed a significant downward trend $(\mathrm{p}<0.05)$. Similarly, all H Codes except for H18 had a significant upward trend $(\mathrm{p}<0.000)$. As such, K Codes including K45, K56 and K81 had an increasing movement. S Codes also experienced both increasing and decreasing trends. However, none of the $\mathrm{O}$ Codes changed according to time. Other global surgical codes like C61, E07, M51, L60, J98 ( $<<0.000)$, I84 ( $<<0.031)$ and I86 $(p<0.000)$ shown upward and downward trends. Total global surgeries trend was significantly upwards $(B=24.26109, \mathrm{p}<0.000)$.

Conclusion: The varying trend of global surgeries can partly reflect the behavior of service providers in order to increase their profits and minimize their costs.
\end{abstract}

Keywords: Global Payment System, Time Series Analysis, Surgical Operation, Iran

\section{Introduction}

Decisions and actions of health care professionals greatly affect care outcomes such as cost, quality and justice. There is a widespread belief that professionals' behaviors are determined by how and how much to pay them (1). In the health sector, customers are usually not able to assess their need for health services, and so they rely on the advice of health care providers about the appropriateness of treatment strategies, consequently health care providers

\section{Corresponding author:}

Associate Professor Dr. Ebrahim Jaafaripooyan, Department of Health Management and Economics, School of Public Health, Tehran University of Medical Sciences, Tehran, Iran.

Tel: +98.2142933058 Fax: +98.2188989129, Email: jaafaripooyan@tums.ac.ir

Received: July 30, 2017, Accepted: October 04, 2017, Published: March 2018

iThenticate screening: September 28, 2017, English editing: February 26, 2018, Quality control: March 10, 2018

This article has been reviewed / commented by four experts

(C) 2018 The Authors. This is an open access article under the terms of the Creative Commons Attribution-NonCommercialNoDerivs License, which permits use and distribution in any medium, provided the original work is properly cited, the use is non-commercial and no modifications or adaptations are made. 
have a great impact on the supply and demand for health care services (2). Payment method creates strong incentives which cause physicians to accordingly decide how to treat (outpatient, hospitalization, surgery, etc.) (3). Thus, the amount and method of payment to health care providers directly affect the organization and function of the national health system, benefiting patients from the health system and the structure and performance of the insurance organizations $(4,5)$. Reluctance and dissatisfaction of health service providers can lead to a reduction in service quality, increasing the length of stay and ultimately increasing the cost of health care (6). Decision about how to pay is of political nature, because it will leave a great impact on the health system (7). Therefore, it is necessary to consider incentives for physicians and health care providers. There are, overall, various types and categorizations of payment methods to providers in health care, the main of them are retrospective and prospective payment systems (PPS) (8). In the prospective system, the payment to providers is based on the work done in the future; in fact, the providers are informed about the receivable costs for their services before providing services. As such, the costs of services are known from the beginning for patients and a fixed cost is paid to providers $(9,10)$. Since (PPS) causes the reduction of the costs, it is one of the most important interests for policy makers, but this payment system, due to savings in the rate and type of services by providers, may reduce the quality of services and ultimately, damage patient's health (11). One of the most important types of PPS is the per-case payment system (12). Per-case payment is a way to classify patients according to their clinical similarities and resource homogeneity (13). In the per-case payment system, the buyer of the service, such as a health insurance organization or patient, pays a certain amount to all hospitals per each treatment case. The payment amount for each case is defined based on one of the global average cost indicators for all hospital cases, the average of cost per case in each hospital ward or an average cost per each case in the patient's diagnostic group (14). In Iran, according to the existing health system structures, there are different payment systems to pay the costs incurred by providers (doctors and hospitals) that each of these systems creates different incentives for service providers and are used in different levels of service delivery in the health system (15). Global payment system, as an example of the per-case payment system which has been employed since 1999 in Iran, used to pay for second and third levels of service delivery. In this system, 60 items of commonly used surgical operations have been specified, and payment for these items is done by the average cost per case. In global payment, total cost of each surgery is calculated by the average of total cost of operation, assistant surgeon, surgery room, anesthesia, hoteling, visiting, counseling, testing, radiology and other costs of the case based on the evaluation degree of the hospital (16). In this system, in corporation with the Ministry of Health and Medical Education (MOHME) and representatives of the basic insurance organizations, a number of operations (60 major operations) were selected, and after being studied by experts according to the average cost of statements for these operations, their tariffs were determined as an overall figure. Accordingly, the insurers, regardless of the cost of hospital, pay a fixed amount to hospitals to do a global operation (17). Since the global payment system in Iran is somehow similar to PPS such as diagnostic related groups or per-case, and acts in order to limit the costs, it is associated with the motivation for providers' behavior change in order to compensate the cost and profit maximization which is one of the most important examples of behavior change, excluding the surgical operation from the global document and doing it as non-global. According to this reality that the global payment system is the first PPS in Iran, and after more than one decade of its implementation, there is no study of its effectiveness or deployment. In addition, given the challenges of this type of payment system and increasing the incentives to change the providers' behaviors in order to offset the cost through decreasing quality and quantity of health services, we decided to study a number of surgical procedures whose costs are paid under the global payment system in the period of ten years (from 2005-2015) which there was reliable recorded data, and determine the amount of reduction, increase or no change in the trend of global operations using time series analysis.

\section{Material and Methods}

\subsection{Research design and data collection}

This is a retrospective longitudinal study within which, the quantitative analysis of time series was used in order to determine the decreasing, increasing or constant trend of global surgery operations (3). The study was conducted based on data from the Health Insurance Organization (HIO) of Tehran province for the period of 2005-2015. HIO is the most known basic insurance organization in Iran and has covered nearly half of the country's population $(38,883,398)$. Since the electronic record of information upon global documents has been available from 2005, this point was considered as the start for collecting data. Secondary data were used in Excel's file format from HIO data bank. The number of total operation documents gathered was 474,071. Information on 60 primary global surgery codes (Table 1) for the period was extracted separately for each month, and in all Tehran province hospitals that follow the global system issued by the MOHME. Out of the 60 surgery codes, 46 codes have been implemented in accordance with insurance documents sent by medical centers. These surgery codes were analyzed in time series model through regression analysis using STATA v.11. 
Table 1. Global surgical operations and their ICD10 codes.

\begin{tabular}{|c|c|c|c|c|c|}
\hline $\begin{array}{l}\text { Operatio } \\
\text { n Code }\end{array}$ & Operation Name & $\begin{array}{l}\text { Number of } \\
\text { total } \\
\text { operations }\end{array}$ & $\begin{array}{l}\text { Operation } \\
\text { Code }\end{array}$ & Operation Name & $\begin{array}{l}\text { Number of } \\
\text { total } \\
\text { operations }\end{array}$ \\
\hline $\mathrm{C} 50$ & Malignant neoplasm of breast & 1656 & N 20 & Kidney or ureter stones & 4208 \\
\hline C61 & Malignant neoplasm of prostate & 786 & $\mathrm{~N} 28$ & Kidney and ureter disorders & 768 \\
\hline E07 & Thyroid disorders & 1957 & N 32 & Bladder disorder & 973 \\
\hline G91 & Hydrocephalus & 547 & $\mathrm{~N} 42$ & Prostate disorders & 1832 \\
\hline H18 & Corneal disorders & 50 & $\mathrm{~N} 43$ & Hydrocele and sperm tool & 1018 \\
\hline $\mathrm{H} 25$ & Age cataract & 92846 & $\mathrm{~N} 45$ & Orchids and epididymitis & 1733 \\
\hline $\mathrm{H} 35$ & Retinal disorders & 6296 & N63 & Non-specific breast masses & 2656 \\
\hline $\mathrm{H} 50$ & Strabismus & 9404 & N81 & Female genital prolapse & 3312 \\
\hline $\mathrm{H} 72$ & Tympanic membrane perforation & 7336 & N83 & $\begin{array}{l}\text { Non-inflammatory disorders of the ovaries and } \\
\text { fallopian tubes }\end{array}$ & 2936 \\
\hline I84 & Hemorrhoids & 6757 & N90 & Non-inflammatory disorders of vulva and perinea & 180 \\
\hline I86 & Varicose veins & 3115 & N93 & Abnormal bleeding of uterus and vagina & 14218 \\
\hline $\mathrm{J} 34$ & Disorders of the nose and sinuses & 3156 & $\mathrm{O} 00$ & Ectopic pregnancy & 1105 \\
\hline $\mathrm{J} 35$ & $\begin{array}{l}\text { Tonsils and adenoids chronic } \\
\text { diseases }\end{array}$ & 7611 & O05 & Other abortions & 14772 \\
\hline J98 & Respiratory disorders & 367 & O81 & Singleton delivery with forceps or vacuum & 161862 \\
\hline K35 & Acute appendicitis & 19654 & 082 & Singleton cesarean section delivery & 48873 \\
\hline $\mathrm{K} 40$ & Inguinal hernia & 19920 & S02 & Skull and facial bone fractures & 2364 \\
\hline K45 & Abdominal hernias & 3743 & S42 & Shoulder and upper arm fracture & 98 \\
\hline K56 & Paralytic ileus & 607 & S43 & $\begin{array}{l}\text { Dislocation and screw corrosion of joints and } \\
\text { ligaments, shoulders and upper arm }\end{array}$ & 790 \\
\hline K81 & Cholecystitis & 11117 & S52 & Forearm fracture & 1643 \\
\hline K92 & Gastrointestinal diseases & 338 & S64 & Damage to the nerves in the wrist and fingers & 2837 \\
\hline L05 & Pilonidal cyst & 5984 & S68 & Traumatic amputation of wrist and fingers & 748 \\
\hline L60 & Nail disorders & 515 & S72 & Fracture of femora & 367 \\
\hline M51 & Intervertebral disc disorders & 935 & S82 & Fracture of leg & 81 \\
\hline J33* & Nasal Polyp & 0 & S02.2* & Nasal Fracture & 0 \\
\hline D73* & Splenitis (Diseases of Spleen) & 0 & Q53* & Cryptorchism? & 0 \\
\hline S36* & Rapture of Spleen & 0 & $\mathrm{C} 73^{*}$ & Malignant Neoplasm of Thyroid Gland & 0 \\
\hline O04* & Dilation or Curtage of Uterus & 0 & M48* & Spinal Stenosis & 0 \\
\hline S31* & $\begin{array}{l}\text { Open Wound of Vagina and } \\
\text { Valva }\end{array}$ & 0 & N81.1* & Cystocele & 0 \\
\hline S04-8* & $\begin{array}{l}\text { Examination and Observation for } \\
\text { Other Reasons? }\end{array}$ & 0 & K56.5* & intestinal obstruction & 0 \\
\hline C66* & Malignant Neoplasm of Ureter & 0 & I86.1* & Varicocele & 0 \\
\hline \multicolumn{5}{|c|}{ Total number of the global surgery codes } & 474071 \\
\hline
\end{tabular}

*The global surgical codes with no operation documents and zero frequency in $\mathrm{HIO}$ which were excluded from the study.

\subsection{Data analysis method}

The data were analyzed using time series analysis through regression model in the environment of STATA v.11. A time series is a set of statistical data collected at regular and equal intervals $(9,18)$. Global payment system was lunched in 1999, but due to there being no recorded data until November 2005, we started to collect data from Nov 2005 to Sep 2015. Data were entered into the model which was composed of 107 time points (13 months missed), because of some structural reform (Health Transformation Plan) and changes in global surgical codes and tariffs and impossibility of tracking and matching data, information related to the second sixth month of 2015 was removed from the time trend data. Finally, the results obtained from the analysis of findings using STATA v.11. can be shown in the form of polynomial curve charts.

\subsection{Ethical considerations}

In order to observe the ethical considerations, for using data from HIO of Tehran Province, the relevant licenses were obtained. The names of healthcare centers where we examined the information of the global documents 
remained confidential. This project with code number IR.TUMS.REC.1394.181 was approved by the Ethics Committee of Tehran University of Medical Sciences.

\section{Results}

Data analysis revealed both significant increasing and decreasing as well as non-significant trends in the application of 46 global surgical operation codes by the hospitals in the study period. In fact, the global documents sent by hospitals to insurance bodies have grown in the early years of data recording related to the implementation of this policy, representing a higher interest in the global payment system. Figure 1 displays the global $\mathrm{H}$ code surgeries with $\mathrm{H} 25$ code $(\mathrm{N}=92846)$ of the most number of operation documents among this group with a very distinct and increasing trend $(\mathrm{B}=4.556653, \mathrm{p}<0.000)$. Other codes including $\mathrm{H} 35(\mathrm{~B}=0.3835302, \mathrm{p}<0.000), \mathrm{H} 72(\mathrm{~B}=0.2466349$, $\mathrm{p}<0.000)$, and $\mathrm{H} 50(\mathrm{~B}=0.7896119, \mathrm{p}<0.000)$ have had significant increasing trends during the study period too, although $\mathrm{H} 18(\mathrm{~B}=0.0140089, \mathrm{p}<0.105)$ had a non-significant trend.

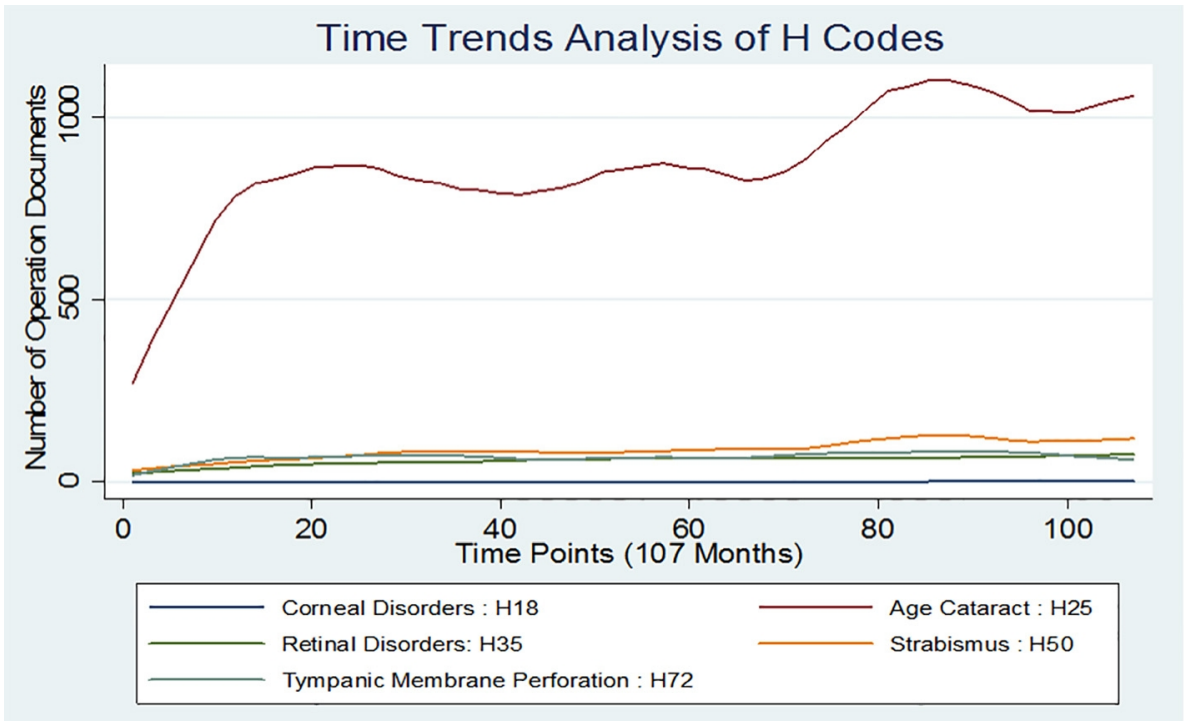

Figure 1. Global surgical operations with $\mathrm{H}$ code

In Figure 2, the surgical operations of $\mathrm{K} 81(\mathrm{~B}=0.6742099, \mathrm{p}<0.000), \mathrm{K} 56(\mathrm{~B}=.041821, \mathrm{p}<0.000)$ and $\mathrm{K} 45$ $(\mathrm{B}=0.1051157, \mathrm{p}<0.007)$ followed significant upward trends while $\mathrm{K} 35(\mathrm{~N}=19654),(\mathrm{B}=0.0795372, \mathrm{p}<0.633)$ and K40 $(\mathrm{N}=19920),(\mathrm{B}=0.0974353, \mathrm{p}<0.537)$ codes with the highest number of operation documents, along with K92 $(\mathrm{B}=0.0040851, \mathrm{p}<0.511)$ had a non-significant increasing trend. In Figure 3, the surgical operation with N93 code $(\mathrm{N}=14218),(\mathrm{B}=0.2329199, \mathrm{p}<0.048)$ has had the most number of operation documents among this group with a significant upward trend. Furthermore, N83 $(\mathrm{B}=0.1551363, \mathrm{p}<0.000), \mathrm{N} 20(\mathrm{~B}=0.1522267, \mathrm{p}<0.000)$, and $\mathrm{N} 28$ $(B=0.0746194, p<0.010)$ have had significant and fairly upward trends, whilst $N 32(B=-0.0297028, p<0.055), N 43$ $(\mathrm{B}=-0.1376398, \mathrm{p}<0.000), \mathrm{N} 81 \quad(\mathrm{~B}=-0.1006289, \mathrm{p}<0.026)$ and $\mathrm{N} 90(\mathrm{~B}=-0.014244, \mathrm{p}<0.008)$ have shown significant downward trends. As such, N45 $(\mathrm{B}=0.0194851, \mathrm{p}<0.334), \mathrm{N} 63(\mathrm{~B}=0.0429573, \mathrm{p}<0.076$, and N42 $(\mathrm{B}=0.0246086, \mathrm{p}<0.351)$ have had a non-significant increasing trend. 


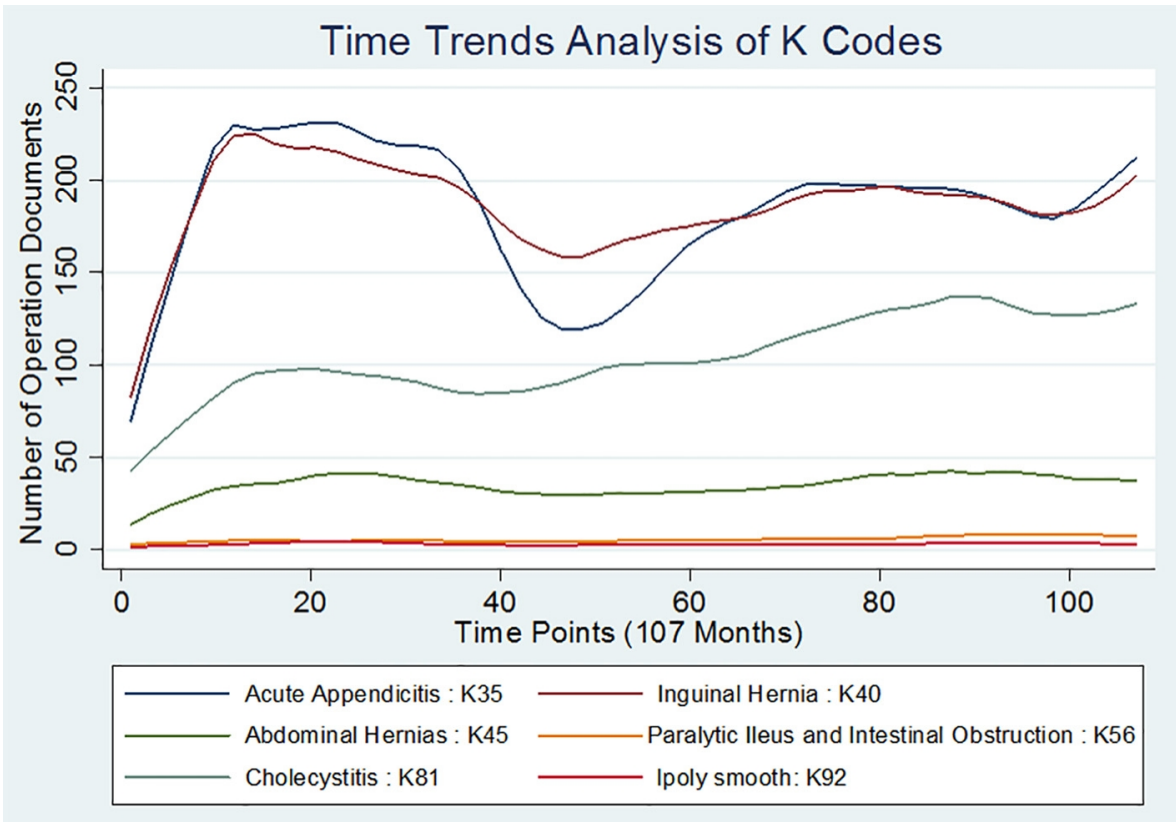

Figure 2. Global surgical operations with $\mathrm{K}$ code

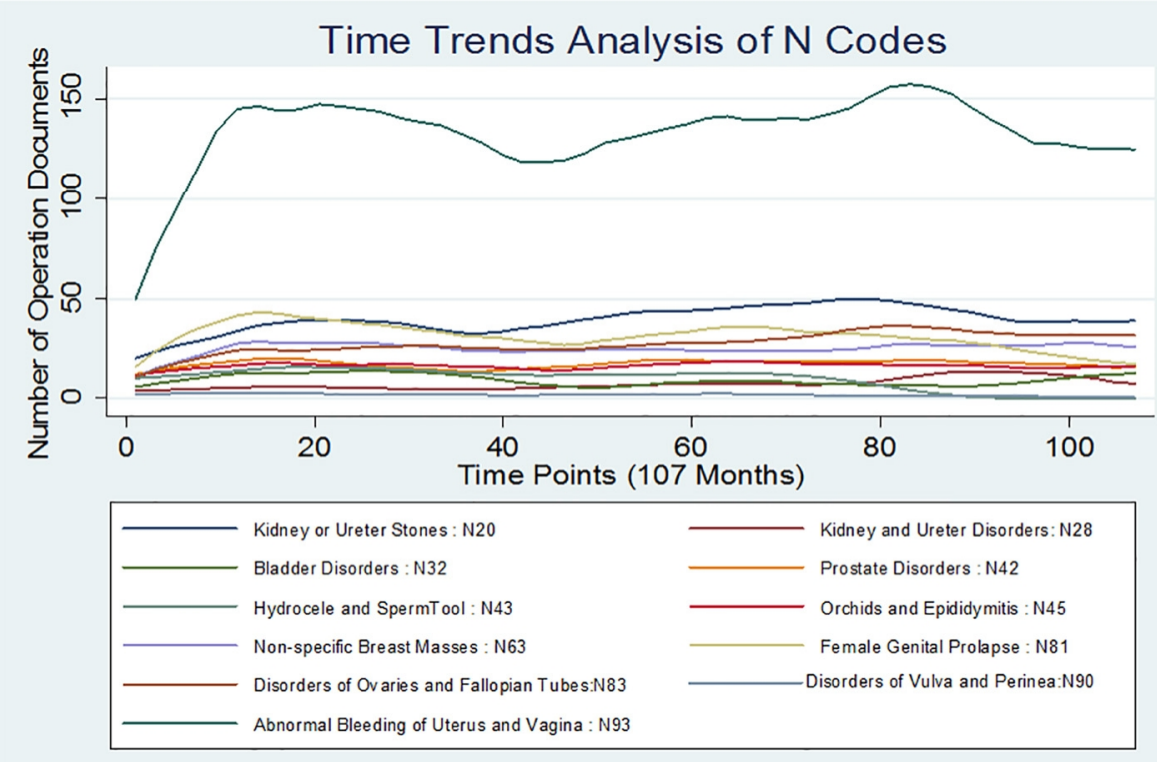

Figure 3. Global surgical operations with $\mathrm{N}$ code

In Figure 4, the surgical operation with $\mathrm{O} 00(\mathrm{~B}=0.0360019, \mathrm{p}<0.084)$ and $\mathrm{O} 81(\mathrm{~B}=1.452624, \mathrm{p}<0.192)$ codes $(\mathrm{N}=161862)$, have had non-significant upward trends while $\mathrm{O} 05(\mathrm{~B}=-0.1951547, \mathrm{p}<0.208)$ and $\mathrm{O} 82(\mathrm{~B}=$ $0.5669978, \mathrm{p}<0.189)$ have followed non-significant downward trends. In Figure5, the surgical operation $\mathrm{S}$ codes including S68 $(B=0.0727777, p<0.000), S 72(B=0.0301044, p<0.008)$ and $\mathrm{S} 64(B=0.9168283, p<0.000)$ have had significant upward trends while $\mathrm{S} 42(\mathrm{~B}=0.0013127, \mathrm{p}<0.719)$ had a non-significant increasing trend. Moreover, S52 $(B=-0.0682811, p<0.001)$, and $S 82(B=-0.0050158, p<0.078$, significant at $\mathrm{p}<0.1)$ showed significant downward trends except S02 code $(\mathrm{N}=2364),(\mathrm{B}=-0.0152139, \mathrm{p}<0.546)$ with the most number of operation documents among this group and S43 $(B=-0.0198476, p<0.124)$ which have followed a non-significant downward trend. (Available data has been recorded for S64 code since 2012, so we exclude it in the analysis). 


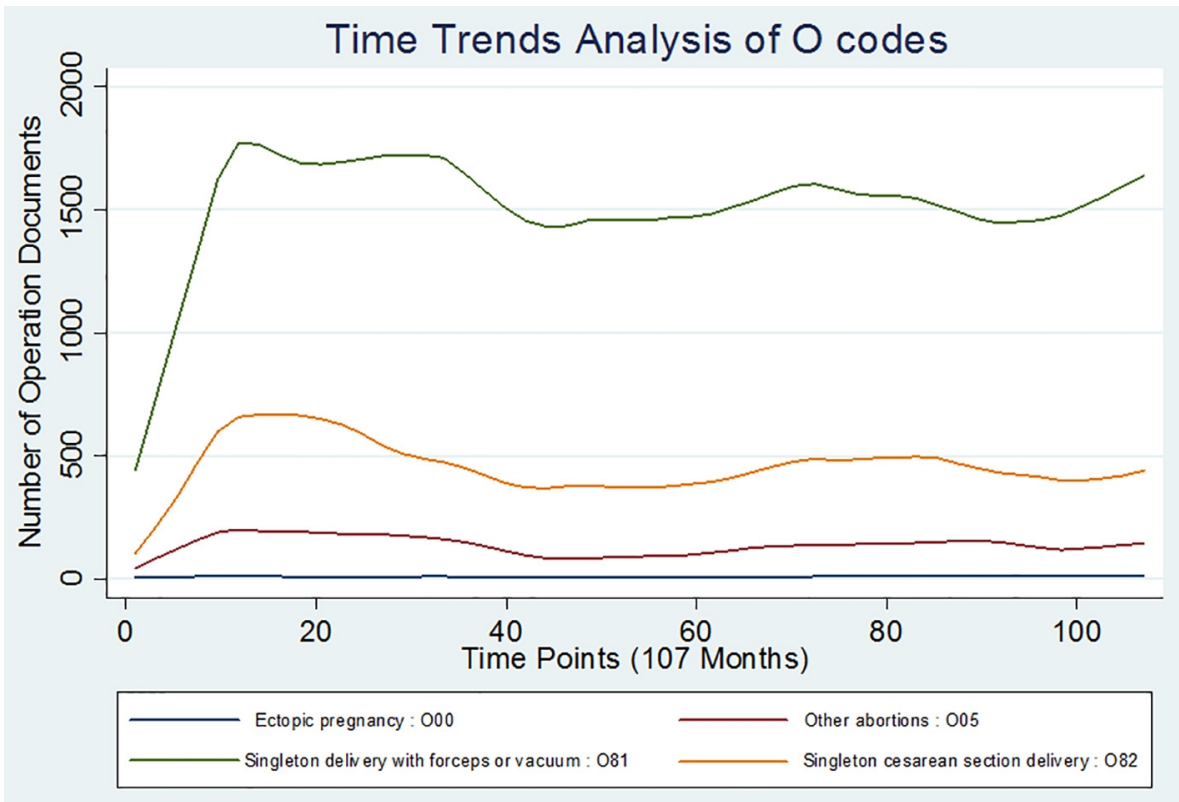

Figure 4. Global surgical operations with $\mathrm{O}$ code

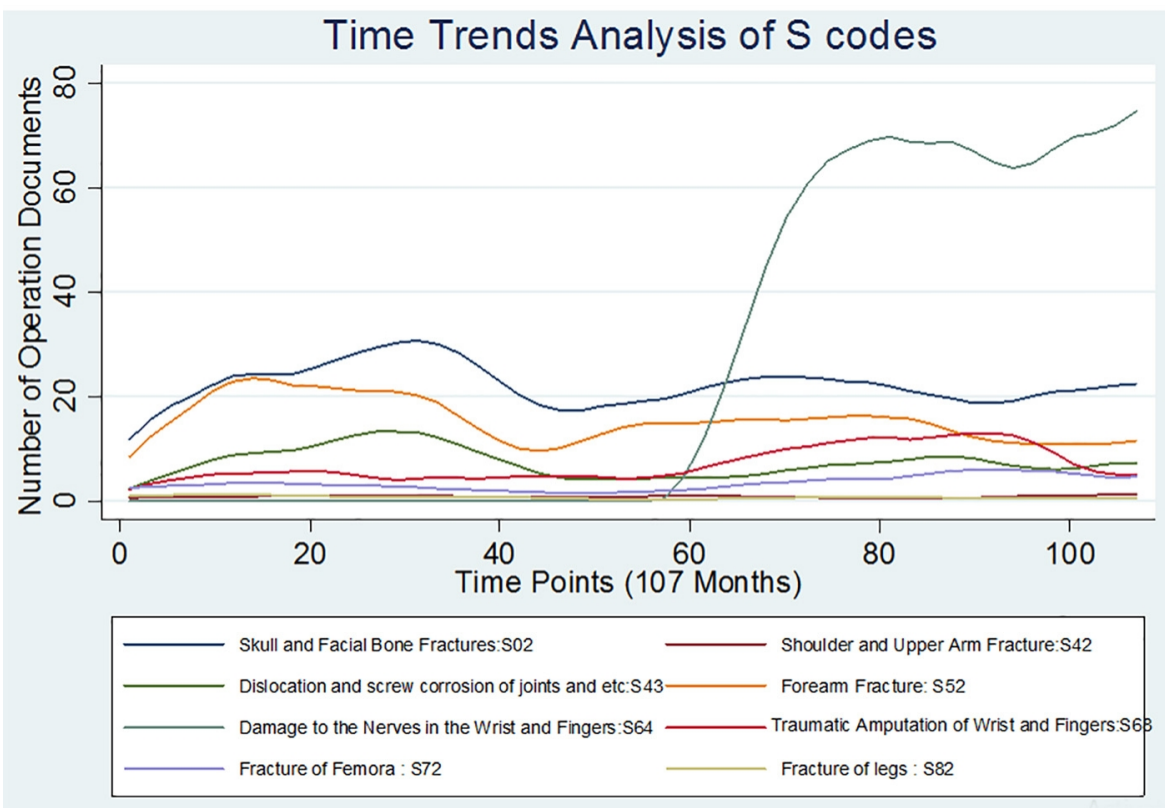

Figure 5. Global surgical operations with $\mathrm{S}$ code

In Figure 6, the surgical operations including $\mathrm{C} 61(\mathrm{~B}=0.2664531, \mathrm{p}<0.000), \mathrm{E} 07(\mathrm{~B}=0.0873744, \mathrm{p}<0.000), \mathrm{M} 1$ $(B=0.0783323, p<0.000), L 60(B=0.0710927, p<0.000), J 98(B=0.052597, p<0.000)$ have shown significant upward trends, while I84 $(\mathrm{N}=6757),(\mathrm{B}=-0.131664, \mathrm{p}<0.031), \mathrm{I} 86(\mathrm{~B}=-0.2529634, \mathrm{p}<0.000)$ have followed significant downward trends. L05 $(\mathrm{N}=5984)(\mathrm{B}=-0.0343267, \mathrm{p}<0.535)$ and $\mathrm{J} 43(\mathrm{~B}=-0.0561531, \mathrm{p}<0.141)$ codes have both shown non-significant downward trends meanwhile $C 50(B=0.020739, p<0.214, G 91(B=0.0021454, p<0.833)$ and $\mathrm{J} 35(\mathrm{~B}=0.0627069, \mathrm{p}<0.557)$ revealed non-significant upward trends. 


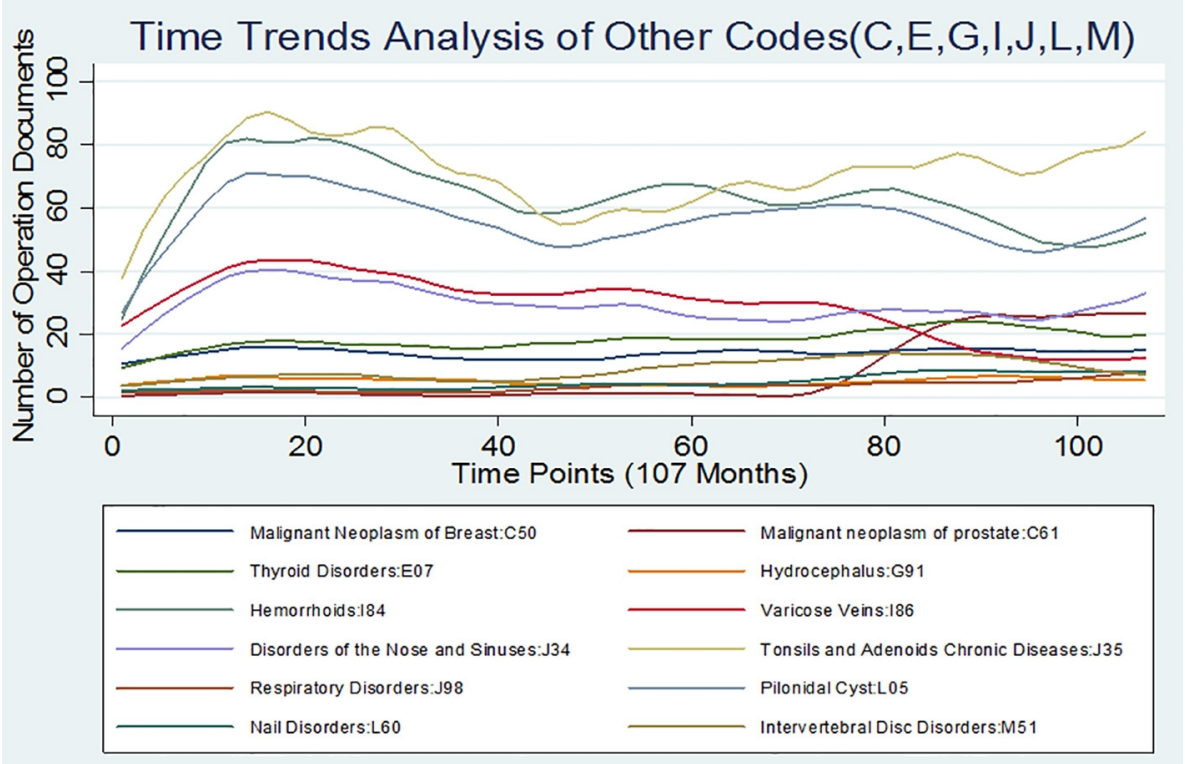

Figure 6. Other global surgical operations

\section{Discussion}

The findings showed that out of 60 global surgical operation codes monthly, the global documents for 46 operation codes are requested in public medical centers, and for the rest of the operation codes, the costs are paid to centers as open or non-global documents. In some cases, the number of the global surgeries have had a decreasing trend and in other cases, they have had increasing or non-significant trends. Findings show that $45.65 \%$ of the global surgery codes have had significant upward trends in the form of global document, while $23.91 \%$ of them have shown a nonsignificant upward trend. In contrast, $17.39 \%$ of these global surgery codes have had significant downward trends and $13.04 \%$ of them have followed non-significant decreasing trends. This finding also puts forth the relationship between decreasing or increasing trends of global surgeries and the behavior of healthcare providers on maximizing profits and compensating the costs. If the surgical operation in the form of a global system is profitable for the hospital, it follows this payment method and if the expenses of surgery exceed the average global fee, the operation is excluded from the global document and is sent to the insurer as an open document. The latter could happen when an operation is associated with complexity or the patient needs specialized care, as well as when the global operation code is also registered with a non-global operation code. According to the results, the downward trend of global surgical procedures may indicate loss of this type of operation in the context of global document for hospitals exclusion of them from global form. Various studies point to similar experiences in different countries with different kinds of case-based payment system like global. For instance, a study by Chen et al. on the behavior of providers in the PPS based on global budgeting in Taiwan showed that the majority of hospitals had lessened their services given to patients to reduce the cost. On the other hand, an induced demand in presenting the profitable services, such as radiology and medicines was observed (19). Also, Giorgio et al. in a study to evaluate the effects of the payment system of global budget on the costs, concluded that the average overall cost has decreased one percent. As a result, nearly $9 \%$ of the costs have reduced within 5 years after the reform (20). On the contrary, Kantarevic and Kralj in their study, examined the behavior of primary care providers after the removal of incentives in the per-case system. The results indicated that the removal of incentives did not influence the behavior of providers (21), which the difference in results shows the need for further investigation. Esmaili et al. in a qualitative study under the title of "the experience to deploy risk-adjusted capitation system for family physicians in Iran, shows that physicians are aware of various impacts associated with per-case payment and react to them. Implementing risk adjustment payment system can lead to effective results (5). In another study by Thompson and McVeigh, on reviewing performance of rehabilitation hospitals both in terms of operating and financing in the periods before and after the implementation of PPS, showed that all profit and non-profit rehabilitation hospitals reduced length of stay and increased discharging and profitability, and simultaneously, the managers of the hospitals adapted their administrative practices in line with financing incentives related to PPS (22). The results of a study on the efficiency of hospitals under the PPS by Herwartz and Strumann have shown that the negative effect could be due to the incentive to hospitals to create financial rewards after the use of this reform (23). Another study that expressed the risks of PPS has shown it has reduced the overall medical costs and length of stay and at the same time, it has 
increased the readmission rates. According to this study, the use of this type of PPS has been associated with a decline in productivity of resources, but it has not increased the quality of health care provided (24). This finding shows the declining quality of services in the form of early discharge and reduced quality in the form of increasing the re-admission rate as the consequences of PPS. Arab et al. in a study to calculate the global costs of the surgical operations in comparison with the calculation of their non-global costs of the surgical operations in 2003-2004 showed that the difference between the costs of global operations paid to the hospitals by the insurers, compared with their actual costs, have decreased. The cause of the significant difference has been stated as the lack of attention to the actual inflation rate in health sector, type of hospital, and the existence of other diseases in patients in determining the global tariffs (25). This finding reflects the important role of risk adjustment variables in realization of payment system tariff which can modify the motivation of service providers. Clair et al. showed that using PPS resulted in increasing surgical complications, readmission rate and costs through induce demands (26). Also, He et al. in a similar study, showed that Global payments was accompanied with growth costs, increased readmission rate and being out of pocket, and emphasized that these payment systems should be used cautiously (27). On the other hand, Moran and Jacobs suggested that cost containment goals under PPS should consider provider's incentives and patient outcomes (28). Regarding this point that data were collected from HIO in Tehran province, and because of different situations of hospitals, costs, number of residents, and diversity of patients, etc. the generalizability was affected and the results are only referred to Tehran province.

\section{Study limitation}

The use of secondary data and the lack of possibilities to extract information of non-global surgical procedures for these codes in this study, limited the applicable analysis methods for the researcher. The study of the factors affecting the increase or decrease of global surgical operations requires an extensive qualitative study.

\section{Conclusions}

The varying trends of global surgeries can partly reflect the behavior of service providers in order to increase profits and minimize costs. Decreasing trends may show the potential need to revise and update this payment system according to health system and providers requirements. The results suggest that the actualization of tariffs of global surgical procedures, considering the type of treatment center (primary, secondary and tertiary), the finished cost of surgical procedures in different hospitals, risk adjustment variables as patient's age, gender, severity of illness, the underlying diseases and comorbidities, geographical and regional variations in reviewing the components of global payment system can have an influential effect on behavior of health care providers. Besides, the low tariff rates of health services in the country and the lack of appropriate and realistic increase of tariffs, in turn, play an important role in the irrationality of global tariff and losses of hospitals to send their documents in the form of global system.

\section{Acknowledgments:}

This study as a research project (IR.TUMS.REC.1394.181 dated 21/6/2015) was financially supported by Tehran University of Medical Sciences (TUMS). In addition, it was part of a PhD thesis by FBG and was supported by the School of Public Health, Tehran University of Medical Sciences.

\section{Conflict of Interest:}

There is no conflict of interest to be declared.

\section{Authors' contributions:}

All authors contributed to this project and article equally. All authors read and approved the final manuscript.

\section{References:}

1) Rosen B. Professional reimbursement and professional behavior: emerging issues and research challenges. Social Science \& Medicine. 1989; 29(3): 455-62. doi: 10.1016/0277-9536(89)90294-3.

2) Wynia MK, Cummins DS, VanGeest JB, Wilson IB. Physician manipulation of reimbursement rules for patients: between a rock and a hard place. JAMA. 2000; 283(14): 1858-65. doi: 10.1001/jama.283.14.1858.

3) Jacobs VR, Fischer T. A Pragmatic Guide on How Physicians Can Take Over Financial Control of Their Clinical Practice. JSLS. 2012; 16(4): 632. doi: 10.4293/108680812X13517013316438.

4) Shrank W, Ettner SL, Slavin PH, Kaplan HJ. Effect of physician reimbursement methodology on the rate and cost of cataract surgery. Archives of ophthalmology. 2005; 123(12): 1733-8. doi: 10.1001/archopht.123.12.1733. 
5) Esmaeili R, Hadian M, Rashidian A, Shariati M, Ghaderi H. The Experience of Risk-Adjusted Capitation Payment for Family Physicians in Iran: A Qualitative Staudy. Iran Red Crescent Med J. 2016; 18(4): e23782. doi: 10.5812/ircmj.23782. PMID: 27340558, PMCID: PMC4916528.

6) Pillay TD, Skordis-Worrall J. South African health financing reform 2000-2010: Understanding the agenda-setting process. Health policy. 2013; 109(3): 321-31. doi: 10.1016/j.healthpol.2012.12.012. PMID: 23337113.

7) Lagarde M, Blaauw D. Physicians' responses to financial and social incentives: A medically framed real effort experiment. Soc Sci Med. 2017; 179: 147-59. doi: 10.1016/j.socscimed.2017.03.002. PMID: 28279924.

8) McPherson E, Hedden L, Regier DA. Impact of oncologist payment method on health care outcomes, costs, quality: a rapid review. Bio Med Central (BMC). 2016; 5: 160. doi: 10.1186/s13643-016-0341-2.

9) Jegers M, Kesteloot K, De Graeve D, Gilles W. A typology for provider payment systems in health care. Health policy. 2002; 60(3): 255-73. doi: 10.1016/S0168-8510(01)00216-0.

10) Melichar L. The effect of reimbursement on medical decision making: Do physicians alter treatment in response to a managed care incentive? Journal of health economics. 2009; 28(4): 902-7. doi: 10.1016/j.jhealeco.2009.03.004.

11) Liu X, Mills A. The influence of bonus payments to doctors on hospital revenue: results of a quasiexperimental study. Applied health economics and health policy. 2002; 2(2): 91-8. PMID: 14619280.

12) Jang $S$, Nam CM, Lee SG, Kim TH, Park S, Park E. Impact of payment system change from per-case to per-diem on high severity patient's length of stay. Medicine (Baltimore). 2016; 95(37): e4839. doi: 10.1097/MD.0000000000004839. PMID: 27631239, PMCID: PMC5402582.

13) Siddiqui M, Joy S, Elwell D, Anderson GF. The National Commission on Physician Payment Reform: Recalibrating Fee-for-Service and Transitioning to Fixed Payment Models. J Gen Intern Med. 2014; 29(5): 700-2. doi: 10.1007/s11606-014-2785-1. PMID: 24573711, PMCID: PMC4000324.

14) Langenbrunner J, Cashin C, O'Dougherty S. Designing and Implementing Health Care Provider Payment Systems How-To-Manuals. The International Bank for Reconstruction and Development/ The World Bank. 2009: 130. doi: 10.1596/978-0-8213-7815-1.

15) Molavi Verdkejani H, Kamyabi A, Jabarizadeh A, Haghdoust A. Methods of remuneration of general practitioners in the world: a Systematic Review on International Documents. Journal of medical council of islamic republic of iran. 2012; 30(4): 379-89.

16) Safdari R, Ghazi Saeidi M, Goudini A, Monajemi F. Study comparative payment mechanism health insurance in United states of America, Australia and Iran, 87-88. Teb. 2010; 19(2): 41-51.

17) Comparing the global average of invoicing operations in civilian hospitals of Social Security Organization with approved tariff in the first six months of 2009. Department of Economics and planning of treatment Social Security Department. 2010.

18) Robinson JC. Theory and practice in the design of physician payment incentives. Milbank Q. 2001; 79(2): 149-77. doi: 10.1111/1468-0009.00202. PMID: 11439463, PMCID: PMC2751195.

19) Chen B, Fan YV. Strategic provider behavior under global budget payment with price adjustment in Taiwan. Health economics. 2015; 24(11): 1422-36. doi: 10.1002/hec.3095.

20) Di Giorgio L, Filippini M, Masiero G. Implications of global budget payment system on nursing home costs. Health policy. 2014; 115(2): 237-48. doi: 10.1016/j.healthpol.2014.01.017.

21) Kantarevic J, Kralj B. Risk selection and cost shifting in a prospective physician payment system: Evidence from Ontario. Health policy. 2014; 115(2): 249-57. doi: 10.1016/j.healthpol.2013.10.002.

22) Thompson MJ, McCue JM. Performance of freestanding inpatient rehabilitation hospitals before and after the rehabilitation prospective payment system. Health Care Manage Rev. 2010; 35(1): 36-45. doi: 10.1097/HMR.0b013e3181b475de. PMID: 20010011.

23) Herwartz H, Strumann Ch. Hospital efficiency under prospective reimbursement schemes: an empirical assessment for the case of Germany. Eur J Health Econ. 2014; 15: 175-86. Doi: 10.1007/s10198-013-04645.

24) Hamada H, Sekimoto M, Imanaka Y. Effects of the per diem prospective payment system with DRG-like grouping system (DPC/PDPS) on resource usage and healthcare quality in Japan. Health Policy. 2012; 107(2): 194-201. doi: 10.1016/j.healthpol.2012.01.002.

25) Arab M, Zeraati H, Ravangard R, Gholinejad A, Rasooli A. Comparing global-operations reimbursements with their actual costs in the Cancer Institute, Tehran. Journal of School of Public Health and Institute of Public Health Research. 2008; 6(2): 59-66. 
26) Clair AJ, Evangelista PJ, Lajam CM, Slover JD, Bosco JA, Iorio R. Cost analysis of total joint arthroplasty readmissions in a bundled payment care improvement initiative. J Arthroplasty. 2016; 31(9): 1862-5. doi: 10.1016/j.arth.2016.02.029. PMID: 27105556.

27) He R, Miao Y, Ye T, Zhang Y, Tang W, Li Z, et al. The effects of global budget on cost control and readmission in rural China: a difference-in-difference analysis. J Med Econ. 2017; 20(9): 903-10. doi: 10.1080/13696998.2017.1336448. PMID: 28562140.

28) Moran V, Jacobs R. Investigating the relationship between costs and outcomes for English mental health providers: a bi-variate multi-level regression analysis. Eur J Health Econ. 2017: 1-10. doi: 10.1007/s10198017-0915-5. PMID: 28647862. 